$2-2014$

\title{
Enzyme Attached on Polymeric Micelles as a Nanoscale Reactor
}

\author{
Moo-Yeal Lee \\ Cleveland State University \\ Kyung-Jin Hong \\ Tokyo Institute of Technology \\ Seung Pil Han \\ Tokyo Institute of Technology \\ Toshio Kajiuchi \\ Tokyo Institute of Technology
}

Follow this and additional works at: https://engagedscholarship.csuohio.edu/encbe_facpub

Part of the Catalysis and Reaction Engineering Commons

How does access to this work benefit you? Let us know!

Publisher's Statement

The final publication is available at Springer via http://dx.doi.org/10.1007/s11814-013-0277-3

\section{Original Citation}

Lee M, Hong K, Han S, Kajiuchi T. Enzyme attached on polymeric micelles as a nanoscale reactor. Korean Journal of Chemical Engineering. 2014;31:188-193.

\section{Repository Citation}

Lee, Moo-Yeal; Hong, Kyung-Jin; Han, Seung Pil; and Kajiuchi, Toshio, "Enzyme Attached on Polymeric Micelles as a Nanoscale Reactor" (2014). Chemical \& Biomedical Engineering Faculty Publications. 112.

https://engagedscholarship.csuohio.edu/encbe_facpub/112

This Article is brought to you for free and open access by the Chemical \& Biomedical Engineering Department at EngagedScholarship@CSU. It has been accepted for inclusion in Chemical \& Biomedical Engineering Faculty Publications by an authorized administrator of EngagedScholarship@CSU. For more information, please contact library.es@csuohio.edu. 


\title{
Enzyme attached on polymeric micelles as a nanoscale reactor
}

\author{
Moo-Yeal Lee, ${ }^{*,}$, Kyung-Jin Hong**, Seung Pil Han**, and Toshio Kajiuchi** \\ *Department of Chemical and Biomedical Engineering, Cleveland State University, \\ 1960 East 24th Street, Cleveland, Ohio 44115-2214, USA \\ **Department of International Development Engineering, Tokyo Institute of Technology, \\ 2-12-1 Ookayama, Meguro-ku, Tokyo 152-8550, Japan
}

\begin{abstract}
Similar to what lipase does, a surface-active enzyme was developed by attaching peroxidase on combshaped polymaleic anhydride-alt-1-tetradecene (PMA-TD) in a microemulsion system composed of $n$-butyl acetate and buffer solution, and its catalytic characteristics of polyphenol synthesis were investigated in an aqueous solution. The modified peroxidase with PMA-TD tended to form self-assembled aggregates like micelles in the aqueous solution and could be concentrated at solvent/water interfaces without unfolding of the enzyme. The efficiency of conversion of 2,4-dichlorophenol to phenolic oligomers was approximately 2-fold improved with the modified peroxidase compared to native peroxidase. The $\mathrm{K}_{m}$ and $\mathrm{V}_{\text {max }}$ values for the modified peroxidase were 1.5-fold lower and 2-fold higher, respectively. The hydrodynamic diameter of the micelle on the modified peroxidase increased with the reaction time, indicating that phenolic products were accumulated in the hydrophobic interior of micelles. In addition, the molecular weight (MW) of phenolic polymers was much larger in the system with the modified peroxidase. These observations implied that the modified peroxidase with hydrophobic side chains formed micellar structures by solubilization of phenolic products and further polymerization reaction could occur in the hydrophobic interior of the micelles.
\end{abstract}

Keywords: Peroxidase, Chemical Modification, Self-assembled Aggregates, Nanoscale Reactor

\section{INTRODUCTION}

For enzymatic reactions in which substrates are hydrophobic, high rates of reaction can be achieved if the immiscibility of the substrates in aqueous solutions can be overcome. Alternatively, enzymes should be concentrated at a substrate/water interface similar to lipases that are concentrated at an oil/water interface and hydrolyze lipid structures [1,2]. Thus, understanding interfacial phenomena of surface-active enzyme including lipases is particularly important to examine the enzyme activity by the adsorption of these enzymes into interfaces. However, most enzymes cannot catalyze their reactions at the interface because enzymes tend to be soluble only in aqueous solutions and cannot be concentrated at the interface without unfolding [3,4]. To solve the immiscibility problem and catalyze the enzymatic reaction at the interface, an artificial surfaceactive enzyme having a hydrophilic head (enzyme) and a hydrophobic tail (polymer) similar to polymeric surfactants is proposed. To validate the concept of surface-active enzyme, we developed a surface-active peroxidase that had horseradish peroxidase as a hydrophilic head and comb-shaped polymaleic anhydride-alt-1-tetradecene (PMA-TD, average MW 9000) as a hydrophobic tail, and studied its catalytic characteristics in polyphenol synthesis (Scheme 1).

Because peroxidases can catalyze coupling reactions of phenolic compounds through activation by hydrogen peroxide, leading to phenoxyl radical intermediates that can form phenolic oligomers and polymers in aqueous solutions, peroxidases including horse-

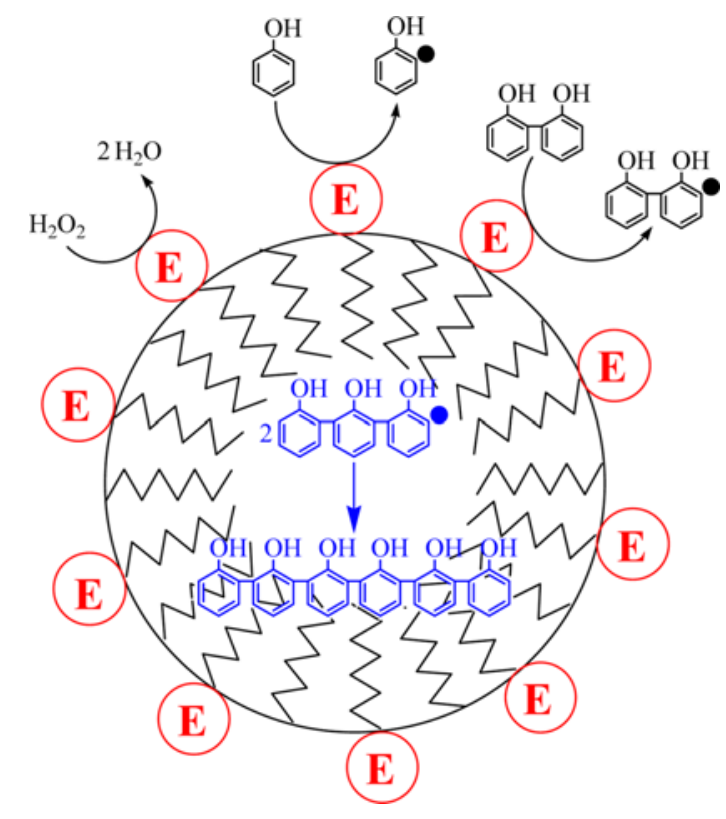

Scheme 1. The concept of surface-active peroxidase as a nanoscale reactor.

radish peroxidase, lignin peroxidase, and manganese peroxidase are often employed to remove phenolic pollutants for bioremediation [5-8]. However, phenolic compounds including chlorophenols are likely to be insoluble in aqueous solutions due to their high hydrophobicity, which makes them difficult to remove from soil. In addition, phenolic products by enzymatic reaction easily precipitate in aqueous solutions due to the increase in hydrophobicity, thereby 
hindering further polymerization reactions. To alleviate these problems, polar solvent including dimethylformamide (DMF) was often added in aqueous solutions in which substrates and products were miscible with peroxidases, so that the system was single phase and rates were not limited by inter-phase transport $[9,10]$. However, adding organic solvents with peroxidase and hydrogen peroxide in soil to dissolve and remediate hydrophobic phenolic compounds seemed unacceptable because organic solvents could be another pollutants in soil. Thus, peroxidase was chemically attached on PMA-TD micelles, eventually improving solubility of phenolic substrates and enzyme accessibility to substrates through the localization of phenolic products. The PMA-TD micelle was expected to solubilize and emulsify hydrophobic phenolic products, while the role of peroxidase was to shuttle the phenolic monomers from the aqueous phase into the micellar environment by changing hydrophobicity of phenolic compounds where further polymerization reactions might take place. In the present work we focused on the following assumptions: (1) the artificial surface-active peroxidase with PMA-TD is catalytically active in the oxidative polymerization of phenolic substrates such as 2,4-dichlorophenol, (2) the modified peroxidase with PMATD can concentrate phenolic products by forming self-assembled micellar structure, and (3) there are further polymerization reactions occurring in the PMA-TD micelles.

\section{MATERIALS AND METHODS}

\section{Materials}

Horseradish peroxidase (264 units/mg, RZ of 3.30) was purchased from Biozyme Laboratories (South Wales, UK). One unit of peroxidase activity is defined as the amount of peroxidase that produces $1.0 \mathrm{mg}$ of purpurogallin from pyrogallol in $20 \mathrm{sec}$ at $20^{\circ} \mathrm{C}$ and $\mathrm{pH}$ 6.0. PMA-TD, supplied by Aldrich Chemical Co. (Milwaukee, WI), was used as a modifier for the chemical modification of peroxidase. The phenolic compound including 2,4-dichlorophenol was obtained from Wako Chemical Ind. (Osaka, Japan). All chemicals were of the highest purity available and were used without further purification.

\section{Chemical Modification of Peroxidase}

Peroxidase was chemically modified in a microemulsion system because PMA-TD is initially insoluble in aqueous solutions. PMATD $(10 \mathrm{mg} / \mathrm{mL})$ was dissolved in $n$-butyl acetate, and the microemulsion system was prepared by vigorous stirring for $30 \mathrm{~min}$ after addition of boric acid-borax buffer $(\mathrm{pH} 8.0)$ at $0{ }^{\circ} \mathrm{C}$. Peroxidase $(1 \mathrm{mg} /$ $\mathrm{mL}$ ) prepared in the buffer solution was added slowly to the microemulsion with gentle mixing for $1 \mathrm{~h}$ at $0{ }^{\circ} \mathrm{C}$. After the modification reaction, the reaction mixture was freeze-dried for $6 \mathrm{~h}$ and the excess PMA-TD was removed by extraction with $n$-butyl acetate. The recovered modified peroxidase with PMA-TD was dissolved in phosphate buffer $(\mathrm{pH} 7.0)$ by mild sonication at $0{ }^{\circ} \mathrm{C}$. The modification degree of amine groups on peroxidase by maleic anhydride groups on PMA-TD was determined by measuring remaining free amine groups on PMA-TD modified peroxidase via a TNBS method [11]. Briefly, a mixture was prepared by adding $1 \mathrm{~mL}$ of $0.1 \%$ 2,4,6-trinitrobenzene sulfonic acid (TNBS), $1 \mathrm{~mL}$ of $10 \mathrm{mM}$ sodium sulfate, $4 \mathrm{~mL}$ of $500 \mathrm{mM}$ borate buffer (pH 9.3), and $1 \mathrm{~mL}$ of PMATD-modified peroxidase solution. The mixture was continuously stirred with a shaker $(80 \mathrm{rpm})$ for $30 \mathrm{~min}$ at $37^{\circ} \mathrm{C}$. The rate of color development at $420 \mathrm{~nm}$ proportional to the number of unmodified amine groups on the modified peroxidase was measured in triplicate. To demonstrate aggregation of the modified peroxidase at a solvent/water interface, $n$-butyl acetate was sprayed on the surface of glass slide and fluorescein isothiocyanate (FITC)-labeled modified peroxidase with PMA-TD in an aqueous solution was added on top of that. The micro-droplets of $n$-butyl acetate with FITClabeled modified peroxidase with PMA-TD were visualized with a Spot RT camera attached to a Nikon Eclipse TE 200 inverted microscope with TE-FM epifluorescence attachment (Micro Video Instruments, Avon, MA).

\section{Polymerization Reaction with Phenolic Compounds and De- termination of Reaction Yield}

A typical reaction mixture consisting of $7 \mathrm{~mL}$ of $100 \mathrm{mM}$ phosphate buffer ( $\mathrm{pH} 7.0), 12.5 \mathrm{~mL}$ of 2,4-dichlorophenol (0.8-8 mM), and $0.5 \mathrm{~mL}$ of PMA-TD-modified peroxidase $(1 \mathrm{mg} / \mathrm{mL})$ was prepared, and an enzymatic reaction was initiated by adding $5 \mathrm{~mL}$ of hydrogen peroxide $(2 \mathrm{mM})$. The reaction mixture was incubated with constant shaking $(80 \mathrm{rpm})$ for $1 \mathrm{~h}$ at $25^{\circ} \mathrm{C}$. To determine the concentration of the remaining 2,4-dichlorophenol in the solution, the mixture was filtered with $0.45 \mu \mathrm{m}$ membrane filter and the filtrate was analyzed by HPLC system (Shimadzu Corp., Kyoto, Japan) equipped with a $25 \mathrm{~cm} \times 4.6 \mathrm{~mm}$ fluofix $120 \mathrm{~N}$ column (Wako Chemical Ind., Osaka, Japan) and a UV absorbance detector operated at $280 \mathrm{~nm}$. The mobile phase was a mixture of acetonitrile and water $(50: 50, \mathrm{v} / \mathrm{v})$, and the analysis was performed under isocratic elution condition at a flow late of $1 \mathrm{~mL} / \mathrm{min}$. The absorbance was subsequently converted to the concentration of 2,4-dichlorophenol using a calibration curve. The phenolic products in the micelles were isolated from the reaction mixture by filtration, washed repeatedly with distilled water to remove soluble materials, and dissolved in DMF at the concentration of $0.1 \mathrm{wt} \%$. After removal of insoluble modified peroxidase with PMA-TD in DMF by centrifugation, $100 \mu \mathrm{L}$ of sample solution was injected into a gel permeation chromatography (GPC) system (Shimadzu Corp., Kyoto, Japan) equipped with a TSK-GEL G1000 $\mathrm{H}_{X L}$ column (Tosoh Corp., Tokyo, Japan) and a UV absorbance detector operated at $270 \mathrm{~nm}$. The mobile phase for analysis of phenolic products was $100 \%$ of DMF and was eluted at a flow late of $0.8 \mathrm{~mL} / \mathrm{min}$. Polystyrene samples in the $\mathrm{MW}$ range of 504-5870 were used as a standard material for the calibration.

\section{Measurement of Hydrodynamic Diameter by DLS}

Dynamic light scattering (DLS) spectrophotometer was used to examine the hydrodynamic diameter of the micelles containing phenolic products on PMA-TD-modified peroxidase at different reaction times. The instrument was composed of an He-Ne laser (632.8 $\mathrm{nm}$ wavelength), a temperature-controlled chamber (with accuracy $\pm 0.1^{\circ} \mathrm{C}$ ), and a photomultiplier at a detection angle of $90^{\circ}$ (DLS7000, Otsuka Electronics Co., Osaka, Japan). The scattered light was analyzed by an autocorrelator using the cumulant method. The hydrodynamic diameter $\left(\mathrm{D}_{H}\right)$ was obtained from the diffusion coefficient (D) and using the Stokes-Einstein relation:

$$
\mathrm{D}_{H}=\mathrm{kT} / 3 \pi \eta \mathrm{D}
$$

where $\mathrm{k}$ is the Boltzmann constant, $\mathrm{T}$ is the absolute temperature and $\eta$ is the solution viscosity. The diffusion coefficient is $\left(2 \tau \mathrm{q}^{2}\right)^{-1}$, with $\tau$ being the exponential decay time and $\mathrm{q}=(4 \pi \mathrm{n} / \lambda) \sin (\theta / 2)$ being the scattering vector. All measurements were conducted at 
$25^{\circ} \mathrm{C}$ as the results of DLS were very sensitive to the temperature.

\section{RESULTS AND DISCUSSION}

For the preparation of the surface-active enzyme, robust and relatively low MW of enzyme such as peroxidase was selected to prevent denaturation of the enzyme during a modification procedure. In addition, comb-shaped reactive polymer with hydrophobic side chains $\left(\mathrm{C}_{12}\right)$ and maleic anhydrides such as PMA-TD was considered as a modifier. Peroxidase and PMA-TD were solubilized in water and $n$-butyl acetate, separately, and a modification reaction was performed in a water (10\%)-in- $n$-butyl acetate $(90 \%)$ microemulsion system for $1 \mathrm{~h}$ at $0{ }^{\circ} \mathrm{C}$. In water- $n$-butyl acetate mixture containing PMA-TD, hydrophilic maleic anhydrides were oriented toward water, and hydrophobic alkyl chains interacted with each other and $n$-butyl acetate via hydrophobic interactions, resulting in microemulsion structures. The maleic anhydride groups reacted with free amine groups, including those in lysine residues and $\mathrm{N}$-terminal residues on the surface of peroxidase in the microemulsion system. The selection of appropriate organic solvent for the preparation of the microemulsion system was one of the crucial factors to retain the activity of peroxidase during the modification procedure, typically because organic solvents induce the alteration of enzyme structure [12-15]. In the experiment, $n$-butyl acetate appeared to be less detrimental to peroxidase compared to other organic solvents (data not shown). The degree of modification was approximately $40 \%$ determined from the amount of free amine groups in the modified peroxidase with PMA-TD compared to native peroxidase. The TNBS method is commonly used to quantify proteins in aqueous solutions by forming trinitrophenylated amino groups, which are highly colored and exhibit maximum spectral absorbance at $420 \mathrm{~nm}$. The prepared modified peroxidase with PMA-TD was soluble in aqueous solutions but insoluble in organic solvents because of hydrophilic peroxidase and carboxylic groups being generated from maleic anhydrides. The interesting properties of the modified peroxidase with PMATD were that it tended to create its own interface by forming very small self-assembled aggregates like micelles in aqueous solutions (Fig. 1). Apparently, the green fluorescent intensity from FITC attached on the modified peroxidase was much higher at the $n$-butyl

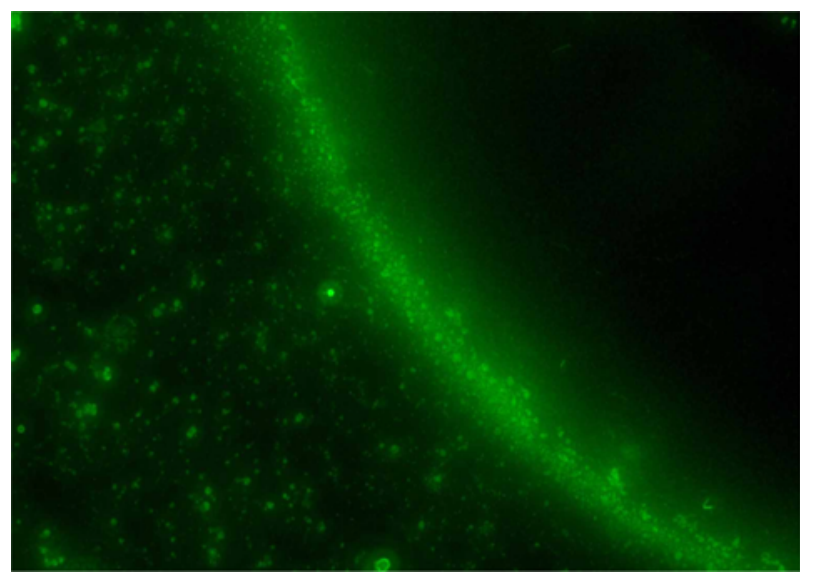

Fig. 1. Micellar aggregates of FITC-labeled modified peroxidase at $\boldsymbol{n}$-butyl acetate/water interface. acetate/water interface than that in the aqueous solution. It implied that peroxidase and carboxylic groups on PMA-TD interacting with water and the alkyl chains on PMA-TD made self-assembled micelle structure in aqueous solutions, which made the modified peroxidase

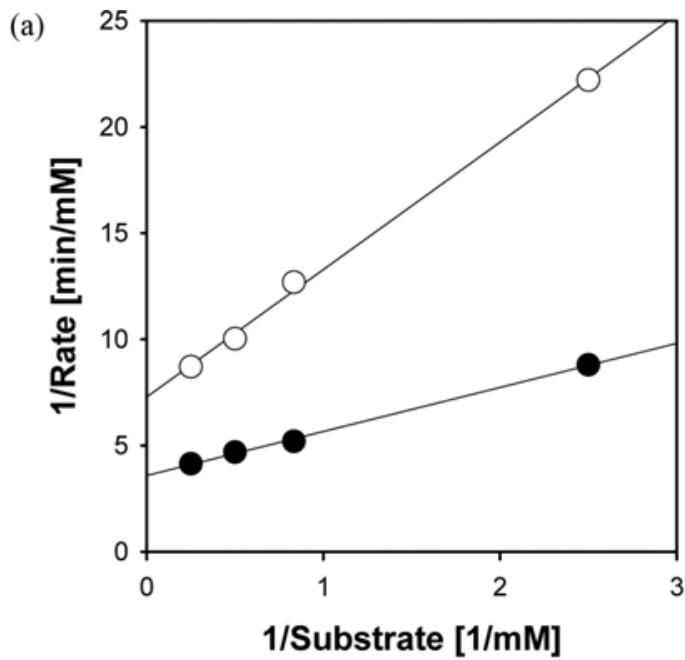

(b)
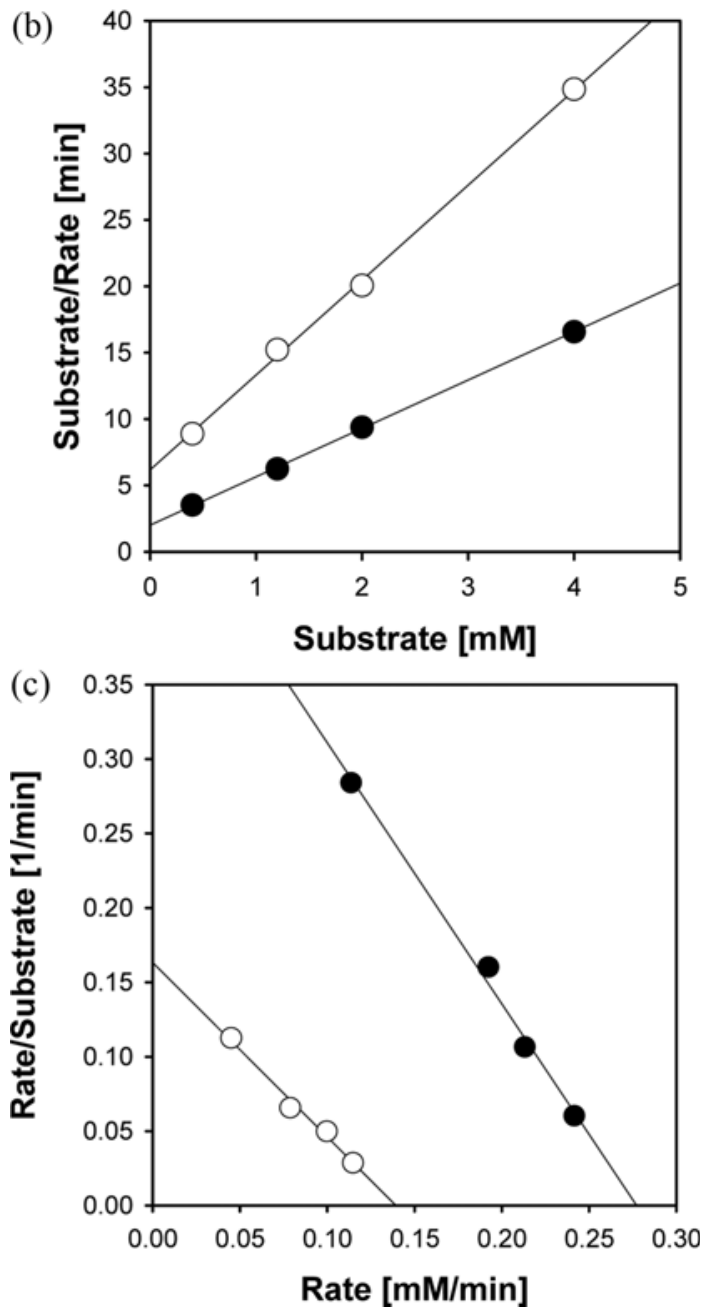

Fig. 2. The calculation of $K_{m}$ and $V_{\text {max }}$ values for $(O)$ native peroxidase and (O) PMA-TD-modified peroxidase with different plots: (a) Lineweaver-Burk, (b) Hanes-Woolf, and (c) Eeadie-Scatcherd. 
Table 1. Calculated $K_{m}$ and $V_{\max }$ values from native peroxidase and PMA-TD-modified peroxidase with different plots

\begin{tabular}{|c|c|c|c|c|c|c|}
\hline \multirow{2}{*}{$\begin{array}{l}\text { Kinetic } \\
\text { parameter }\end{array}$} & \multicolumn{2}{|c|}{ Lineweaver-Burk } & \multicolumn{2}{|c|}{ Hanes-Woolf } & \multicolumn{2}{|c|}{ Eeadie-Scatcherd } \\
\hline & Modified enzyme & Native enzyme & Modified enzyme & Native enzyme & Modified enzyme & Native enzyme \\
\hline $\mathrm{K}_{m}[\mathrm{mM}]$ & 0.577 & 0.824 & 0.551 & 0.863 & 0.568 & 0.848 \\
\hline $\mathrm{V}_{\max }[\mathrm{mM} / \mathrm{min}]$ & 0.278 & 0.137 & 0.275 & 0.139 & 0.277 & 0.138 \\
\hline
\end{tabular}
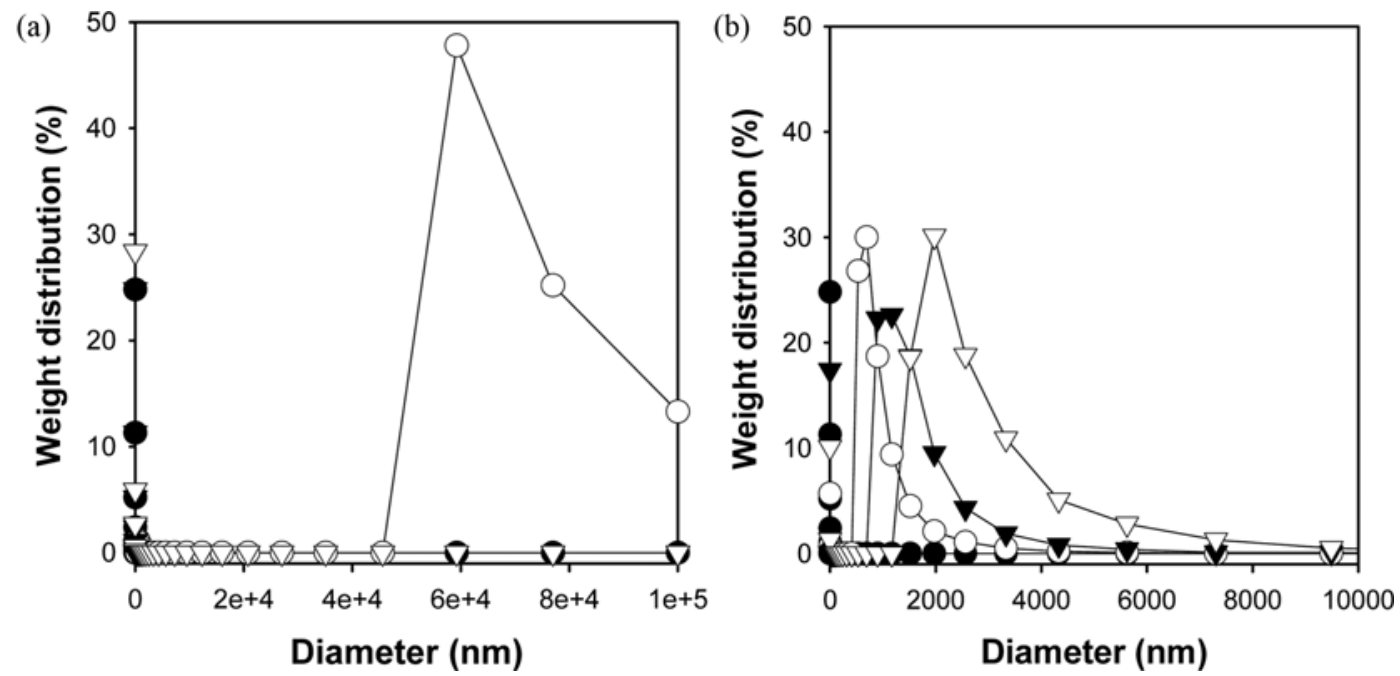

Fig. 3. Analysis of dynamic light scattering (DLS) for the reaction solution containing (a) native peroxidase and (b) the modified peroxidase at different reaction time $(O, 0 \mathrm{~h} ; \bigcirc, 0.5 \mathrm{~h} ; \nabla, 2.5 \mathrm{~h} ; \nabla, 24 \mathrm{~h})$.

with PMA-TD possible to be concentrated at the interface. To investigate the enzyme activity of the modified peroxidase, phenolic polymers were synthesized in the aqueous solution containing the modified peroxidase $(20 \mu \mathrm{g} / \mathrm{mL})$, hydrogen peroxide $(0.4 \mathrm{mM})$, and 2,4-dichlorophenol $(0.4 \mathrm{mM})$ at $\mathrm{pH} 7.0$. The results showed that the efficiency for the conversion of 2,4-dichlorophenol to polymeric products was much more significant in the reaction solution containing the modified peroxidase (ca. 82\%) than native peroxidase (ca. 37\%). From Lineweaver-Burk plots of the Michaelis-Menten equation, kinetic constants of 2,4-dichlorophenol were determined with the modified and native peroxidase (Fig. 2 and Table 1). The $\mathrm{K}_{m}$ and $\mathrm{V}_{\max }$ values for the conversion of 2,4-dichlorophenol with the PMATD-modified peroxidase were calculated to be $0.58 \mathrm{mM}$ and 0.28 $\mathrm{mM}$ phenolic monomer converted/min, respectively, whereas the corresponding values with native peroxidase were $0.82 \mathrm{mM}$ and $0.14 \mathrm{mM}$ phenolic monomer converted/min, respectively. Therefore, the $\mathrm{K}_{m}$ and $\mathrm{V}_{\text {max }}$ values obtained from the PMA-TD-modified peroxidase were 1.5-fold lower and 2-fold higher, respectively, than the corresponding values from native peroxidase. In addition, the catalytic turnover number $\left(\mathrm{k}_{\text {cat }}\right.$ or $\left.\mathrm{V}_{\max } /\left[\mathrm{E}_{0}\right]\right)$ from PMA-TD-modified peroxidase was $14.0 \mu \mathrm{mol}$ phenolic monomer converted $/ \mathrm{mg}$ enzyme-min compared to 7.0 from native peroxidase. Similar results were obtained from Hanes-Woolf and Eeadie-Scatcherd plots (Table 1). The results implied that modification of peroxidase with hydrophobic PMA-TD led to the increase in the affinity of enzyme to the substrate by forming micellar structure with hydrophobic phenolic products, eventually improving enzyme activity. It was remarkable that modification of peroxidase with PMA-TD substantially influenced the substrate affinity and the catalytic efficiency. As a result, the modified peroxidase was found to be significantly effec- tive for the oxidative polymerization of phenolic compounds.

In addition to the remarkable enhancement of catalytic activity of the modified peroxidase, the solution containing the modified peroxidase formed a cloudy suspension in appearance after $24 \mathrm{~h}$ reaction, while the solution with native peroxidase showed a clear supernatant with precipitated phenolic polymers. To determine the hydrodynamic diameter of micellar aggregates, we analyzed the reaction solution with DLS spectrophotometer at different time points (Fig. 3). As a result, the solution with native peroxidase showed polymer aggregates in ca. $60 \mu \mathrm{m}$ diameter within 30 min reaction, and then no further precipitate formed afterward (Fig. 3(a)). This result indicates that 2,4-dichlorophenol was rapidly converted to phenolic polymers via peroxidase catalysis, which led to precipitation of polymer aggregates in aqueous solutions due to their high hydrophobicity. For the PMA-TD-modified peroxidase, the hydrodynamic diameter of the micelles increased with the reaction time (from ca. $500 \mathrm{~nm}$ in $30 \mathrm{~min}$ to ca. $2 \mu \mathrm{m}$ in $24 \mathrm{~h}$ ), implying that phenolic products accumulated in the hydrophobic interior of micelles (Fig. 3(b)). Because the modified peroxidase formed the micellar structure and was capable of catalyzing the synthesis of phenolic polymers, it acted like a nanoscale enzyme reactor having the increasing solubility of hydrophobic polyphenol as well as promoting interfacial reactions on water-insoluble hydrophobic reactants. To investigate the MW of the phenolic polymers in the micelle, the micelles were separated by filtration, and the polymers were extracted using DMF and analyzed by GPC with polystyrene as a standard material for the calibration. Clearly, the degree of polymerization was much higher in the solution with the modified peroxidase than the native peroxidase (Fig. 4). Without adding any organic solvents such as alcohol and DMF, polyphenol with MW 1600-5400 was 


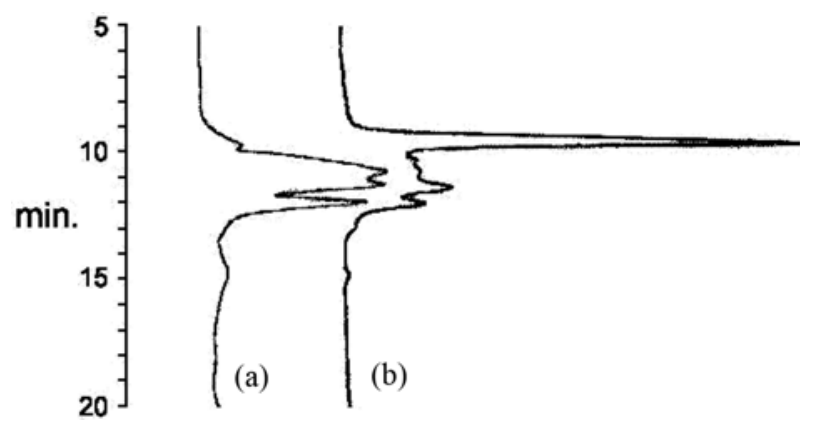

Fig. 4. Molecular weight distribution of the phenolic polymers obtained from the reaction with (a) native peroxidase and (b) the modified peroxidase. The $X$ axis (not shown) represents $\mathrm{UV}$ absorbance measured at $270 \mathrm{~nm}$.

synthesized in the micelles, whereas MW 1400-2600 of polyphenol was synthesized with native peroxidase. The majority of polyphenol synthesized in the micelles had MW around 5000. The result indicated that the hydrophobic interior of micelles on the modified peroxidase could improve the solubility of phenolic oligomers to undergo further polymerization reaction, leading to the formation of higher MW of phenolic polymers due to the organic compound 'dissolving' in the micelles. It is known that degree of polymerization is strongly related to the solubility of the phenolic polymer to sustain the growing chain in aqueous solutions $[10,16]$.

Chemical modification of enzymes was extensively studied using polyethylene glycol (PEG) including comb-shaped PEG with maleic anhydride groups [17-19], surfactant [20], and lipid [21,22], mainly to solubilize enzymes into organic solvents for catalyzing synthetic reactions. PEG, a nontoxic and amphiphatic polymer, is most commonly employed to modify enzymes. The covalent binding of PEG on the surface of enzymes could reduce its antigenic properties, improve thermostability, and enhance stability in organic solvents [23]. However, as far as we know, none of the researches focused on enzyme modification with comb-shaped PMA-TD to improve interfacial properties of enzymes. Recently, polystyrene- $\beta$-galactosidase conjugates, which can be transformed into interface-binding enzyme and form a liquid film through self-assembling, were reported and interfacial transgalactosylation reaction was conducted in a toluene buffer biphasic system [24]. In practice, most enzymes cannot catalyze their reactions at the interfaces because enzymes tend to be soluble only in aqueous solutions and cannot be concentrated at the interfaces without unfolding [25,26]. Proteins exposed to oil/water interfaces exhibited irreversible adsorption because of hydrophobic residues on the protein having a great affinity to the oil phase, resulting in unfolding of protein at the interfaces. Therefore, of prime importance for the modification of enzymes was endowing new properties to delicate enzymes so that modified enzymes cannot lose their activities at interfaces.

The results (interfacial concentration of the modified peroxidase, lower $\mathrm{K}_{m}$ and higher $\mathrm{V}_{\text {max }}$, micelle formation, and higher MW of polyphenol synthesis in the micelles) indicated that the role of peroxidase on the PMA-TD-modified peroxidase was to form phenolic radicals from the monomer in aqueous solution, while the PMATD acted to solubilize the higher MW of phenolic oligomers into the micellar environment where further polymerization reactions primarily took place. The micelles in aqueous solutions appeared particularly attractive in peroxidase oxidation system because the modified peroxidase enabled to synthesize higher MW of phenolic products solubilized in the micellar aggregates without using any organic solvents. In addition, lower $\mathrm{K}_{m}$ and higher $\mathrm{V}_{\max }$ values were presumably because of the enhanced partitioning of phenolic products from the active site of peroxidase to the hydrophobic interior of micelles. The modified peroxidase with PMA-TD acted like polymeric surfactants and hence led to the localization of phenolic products in the micelles. Thus, it was possible to reduce apparent inactivation of peroxidase due to the adsorption of phenolic products to the active site of peroxidase as well as to induce the easier accessibility of phenolic monomers and oligomers at high reaction rates [27-29].

\section{CONCLUSIONS}

The present work demonstrates the application of surface-active peroxidase as a means of a nanoscale enzyme reactor attaining higher reaction rates and conversions than observed with native enzyme. Although the solution containing the modified peroxidase is certainly micro-heterogeneous, it is macroscopically a single, thermodynamically stable phase. The modified peroxidase is concentrated at the interfaces by forming self-assembled micellar structure and showed higher enzyme activity than native enzyme without denaturation. It is remarkable that the kinetic constants for the modified peroxidase are superior to those of the native peroxidase in the aqueous solution. Phenolic polymers are not precipitated in the solution with the modified peroxidase and the hydrodynamic diameter of the micelles increases with the reaction time. In addition, the MW of the polymers in the micelle is much higher than that produced by native peroxidase in the solution. The data appear to validate the assumptions that the modified peroxidase could act like surface-active enzyme and could improve the accessibility of peroxidase to phenolic monomers by localizing phenolic products in the hydrophobic interior of the micelles. The artificial surface-active enzyme can also be applicable to other interfacial enzyme reactions where the solubility of substrates can be a problem.

\section{REFERENCES}

1. K. Faber, Biotransformations in organic chemistry, $2^{\text {nd }}$ Ed. SpringerVerlag: Berlin, Heidelberg (1995).

2. P. Villeneuve, J. M. Muderhwa, J. Graille and M. J. Haas, J. Mol. Catal. B - Enzym., 9, 113 (2000).

3. A. Hickel, C. J. Radke and H. W. Blanch, J. Mol. Catal. B - Enzym., 5, 349 (1998).

4. C. J. Beverung, C. J. Radke and H. W. Blanch, Biophys. Chem., 81, 59 (1999).

5. A. M. Klibanov, T. Tu and K. P. Scott, Science, 221, 259 (1983).

6. A. C. Grabski, H. J. Grimek and R. R. Burgess, Biotechnol. Bioeng., 60, 204 (1998).

7. M. Wagner and J. A. Nicell, Water Res., 36, 4041 (2002).

8. G. Ward, Y. Hadar and C. G. Dosoretz, J. Chem. Technol. Biotechnol., 78, 1239 (2003).

9. M. Ayyagari, K. A. Marx, S. K. Tripathy, J. A. Akkara and D. L. Kaplan, Macromolecules, 28, 5192 (1995).

10. M. Ayyagari, D. L. Kaplan, S. Chatterjee, J. E. Walker and J. A. 
Akkara, Enzyme Microb. Technol., 30, 3 (2002).

11. R. Fields, Biochem. J., 124, 581 (1971).

12. C. Laane, S. Boeren, K. Vos and C. Veeger, Biotechnol. Bioeng., 30, 81 (1987).

13. J. S. Dordick, Enzyme Microb. Technol., 11, 194 (1989).

14. K. G. Ryu and J. S. Dordick, Biochem., 31, 2588 (1992).

15. A. M. Klibanov, Nature, 409, 241 (2001).

16. M. Ayyagari, J. A. Akkara and D. L. Kaplan, Acta Polym., 47, 193 (1996).

17. J. W. Park and T. Kajiuchi, Biotechnol. Bioeng., 45, 366 (1994).

18. M. J. Hernaiz, J. M. Sanchez-Montero and J. V. Sinisterra, Biotechnol. Bioeng., 55, 252 (1997).

19. D. Garcia and J. L. Marty, Appl. Biochem. Biotechnol., 73, 173 (1998).

20. Q. Jene, J. C. Pearson and C. R. Lowe, Enzyme. Microb. Technol.,
20, 69 (1997).

21. J. S. Dordick, Enzyme Microb. Technol., 11, 194 (1989).

22. Y. Okahata and T. Mori, TIBTECH, 15, 50 (1997).

23. R. Villalonga, L. Gomez, H. L. Ramirez and M. L. Villalonga, J. Chem. Technol. Biotechnol., 74, 635 (1999).

24. G. Zhu and P. Wang, J. Am. Chem. Soc., 126, 11132 (2004).

25. A. Hickel, C. J. Radke and H. W. Blanch, J. Mol. Catal. B - Enzym., 5, 349 (1998).

26. C. J. Beverung, C. J. Radke and H. W. Blanch, Biophys. Chem., 81, 59 (1999).

27. J. W. Park, Y. Takahata, T. Kajiuchi and T. Akehata, Biotechnol. Bioeng., 39, 117 (1992).

28. J. Wu and L. K. Ju, Biotechnol. Prog., 14, 649 (1998).

29. T. Eriksson, J. Borjesson and F. Tjerneld, Enzyme Microb. Technol., 31, 353 (2002). 